\title{
SPECTRAL PECULIARITIES OF NH-TAUTOMERISM IN ISOCYCLE-CONTAINING PORPHYRINS AND THEIR COVALENTLY LINKED DIMERS
}

\author{
F.I. ZENKEVICH. A.M. SHULGA. A.V. CHERNOOK and G.P. GURINOVICH \\ Inst it wte of Physics. BSSR A cademy of Sciences, Minsk 220602. USSR \\ Rexered 8 May 1984
}

\begin{abstract}
It has been found experinentally that a whole class of isocycle-containing porphyrins. including synthet ic and natural ubjects and their covalenty linked dimers. shows Nll-tautomerism which manifests itself in isotropic solutions in normal electronie spectra both at $77 \mathrm{~K}$ and higher temperatures (up to $500 \mathrm{~K}$ ).
\end{abstract}

\section{Introduction}

The invest igation of isocycle-containing porphyrins and their dimers has aroused interest for several reasons. First, the isocycle is a structure element of chlorophyll and its natural analogues, and, even more so, it participates in the formation of pigment aggregates [1]. Second. it has been shown recently that the reaction center in photosynthetic systems contains a pair of strongly interacting chlorophyll molecules, the so-called "special pair", which is involved in the initial photophysical processes of the reaction center (see, for example. ref. [2]). So, a synthetic porphyrin dimer in which isocycles are covalently linked may be a good model system for studying natural chlorophyll aggregated forms and photophysical processes in pigment uggregates.

The investigation of such sy'stems requires taking into atcount the possibility of the appearance of some specific effects characteristic of porphyrin molecules. First of all, it is known that in porplyrins two inner hydrogens which. in their stable conformation, are bound to opposite nitrogens. may jump from one pair of nitrogens to another [3]. At room temperature these hydrogens migrate relatively quickly [4]. But at $77 \mathrm{~K}$ the above tautomerism ceases when the porphyrin molecule is in the ground electronic state [5]. The migration of the center protons may still be induced even at liquid-helium temperature by photoexcitation of the porphyrin molecule. Such phototransformation between two tautomers at low temperatures has been observed in two types of experiments: (i) photoinduced reversiblc conversion of admixture centers into one another for porphyrin-free bases incorporated in an n-octane Slrpol'skii matrix [6,7], (ii) variations in the emission intensity and fluorescence depolarization of glassy solutions of porphyrins at $77 \mathrm{~K}$ during excitation by constant polarized monochromatic light [5].

In most cases the spectral separation between the individual tautomers $(\Delta E)$ does not exceed $100 \mathrm{~cm}^{-1}$ $[6,7]$. Therefore $\mathrm{NH}$-tautomerism can be effectively detected at 77 and $4.2 \mathrm{~K}$ in the Shpol'skii matrix only. Accordingly, the fluorescence depolarization due to photoinduced proton migration may be observed only with selective nonochromatic excitation [5]. In chlorins, the spectral separation between the two tautomers is large: $\Delta E \approx 800-1500 \mathrm{~cm}^{-1}$ [8-10]. But the second tautomer which can be produced by photoexcitation can be stable only at $4.2 \mathrm{~K}$ due to the fast reverse photochemical relaxation [10].

Subsequent to a preliminary study of cyclopentanporphyrin NH-tautomerism [11], we present in this paper a more detailed consideration of some new experimental results which show that a whole class of porphyrins - with the isocyclic ring - including natural objects, their derivatives and covalently linked dimers, exhibit $\mathrm{NH}$-tautomerism in isotropic solutions both at $77 \mathrm{~K}$ and at higher temperatures $(500 \mathrm{~K})$, which can be detectable in normal absorption and fluorescence spectra. 


\section{Experimental}

Synthesis and identification of cyclopentanporphyrins and their chemical diners covalently linked via isocycles have been described in previous papers $[12,13]$. The porphyrins with the cyclopentanone ring have been prepared and purified by familiar methods [14-16]. Our experimental results were obtained when investigating the following compounds:

$3^{\prime}, 5^{\prime}$-cyclo-3'-methyl-2,7,8,12.13,17,18-heptaethylporphyrin (1); $3^{\prime}, 5^{\prime}$-cyclo-3'-exomethylen-2,7,8,12, 13,17,18-heptaethyl-22H,24H-porphin (2); phylioerythrin methyl ester (3): deoxophylloerythrin methyl ester (4); 10-ethoxyphylloerythrin methyl ester (5): pheoporphyrin-a 5 dimetlyyl ester (6): 2-vinylpheopor-

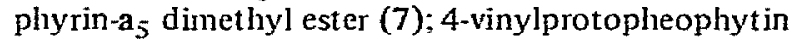
a (8): meso-tripropylcyclopentanporphyrin (9) and $5^{\prime}, 5^{\prime}$-cyclodimer $(10)$ which consists of two molecules 1 and 2:

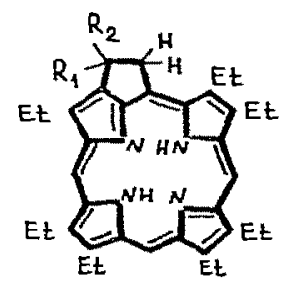

(1), $\mathrm{R}_{1}=\mathrm{H}, \mathrm{R}_{2}=\mathrm{CH}_{3}$

(2), $\mathrm{R}_{1}, \mathrm{R}_{2}==\mathrm{CH}_{2}$

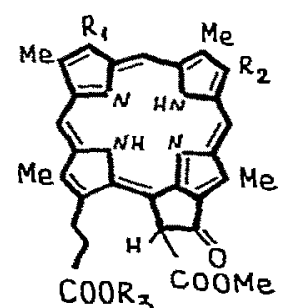

(7), $\mathrm{R}_{1}=\mathrm{CH}=\mathrm{CH}_{2}, \mathrm{R}_{2}=\mathrm{C}_{2} \mathrm{H}_{5}, \mathrm{R}_{3}=\mathrm{CH}_{3}$

(8), $\mathrm{R}_{1}=\mathrm{CH}=\mathrm{CH}_{2}, \mathrm{R}_{2}=\mathrm{CH}=\mathrm{CH}_{2}$

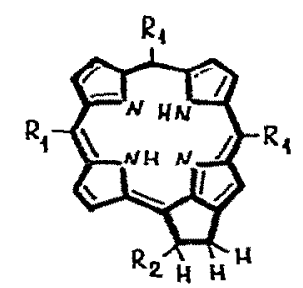

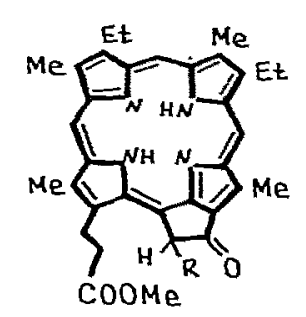

(3), $\mathrm{R}=\mathrm{H}$

(5), $\mathrm{R}=\mathrm{OC}_{2} \mathrm{H}_{5}$

(6), $\mathrm{R}=\mathrm{COOCH}_{3}$

$$
\text { (9), } \begin{aligned}
\mathrm{R}_{1} & =\mathrm{CH}_{2} \mathrm{CH}_{2} \mathrm{CH}_{3} \text {, } \\
\mathrm{R}_{2} & =\mathrm{CH}_{2} \mathrm{CH}_{3}
\end{aligned}
$$

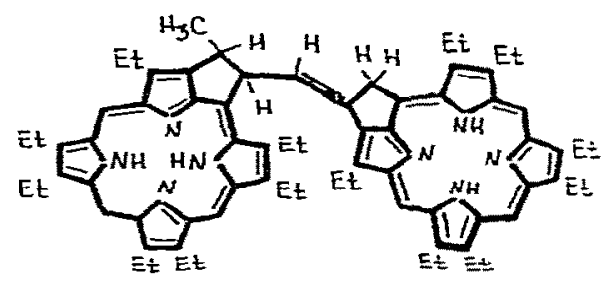

(10)

Compounds 1, 2, 4, 9, 10 were dissolved in EPIP (diethyl ester, petroleun ester, isopropanol $5: 5: 2$ ) at concentrations $\leqslant 10^{-5}$ mol $\ell^{-1}$ whereas compounds $3,5,6,7,8$ were dissolved in THF-DE (tetrahydrofuran, diethyl ester $1: 1$ ) at the same concentrations. These solvent mixtures can be frozen as glassy samples at $77 \mathrm{~K}$. The absorption spectra were recorded on a standard SF-10 spectrophotometer or a Beckman5270. The measurements of fluorescence excitation and emission spectra were made with the aid of an SLM-4800 spectrofluorometer with automatic correction of spectral response.

\section{Results and discussion}

When analyzing in detail the spectroscopic observations of the investigated compounds and symmetrical porphyrins [3], some spectral peculiarities should be emphasized, which are characteristic only of isocyclecontaining porphyrins. Figs. $1-4$ give some experimental results obtained for porplyyrins with different side and isocycle substituents.

(a) Absoption spectra (fig. 1). In most cases, along with the four-band spectrum in the visible region. which is normal for porphyrin free bases [3], an additional real band or shoulder can be observed on the long-wave side of the main $0-0$ absorption band at $293 \mathrm{~K}$. The relative intensity of this new band becomes greater on heating the solutions to $500 \mathrm{~K}$. In contrast, the intensity of the additional band decreases as the solutions are cooled to $77 \mathrm{~K}$ but this band becomes sharper and narrower (fig. $1 \mathrm{~b}$ ).

(b) Fluorescence spectra (fig. 2). At $77 \mathrm{~K}$ the spectra exhibit features common to all objecis: besides the two bands of the main product, there is a new system of bands which corresponds to the additional absorbing center. The relative intensity of these new bands 


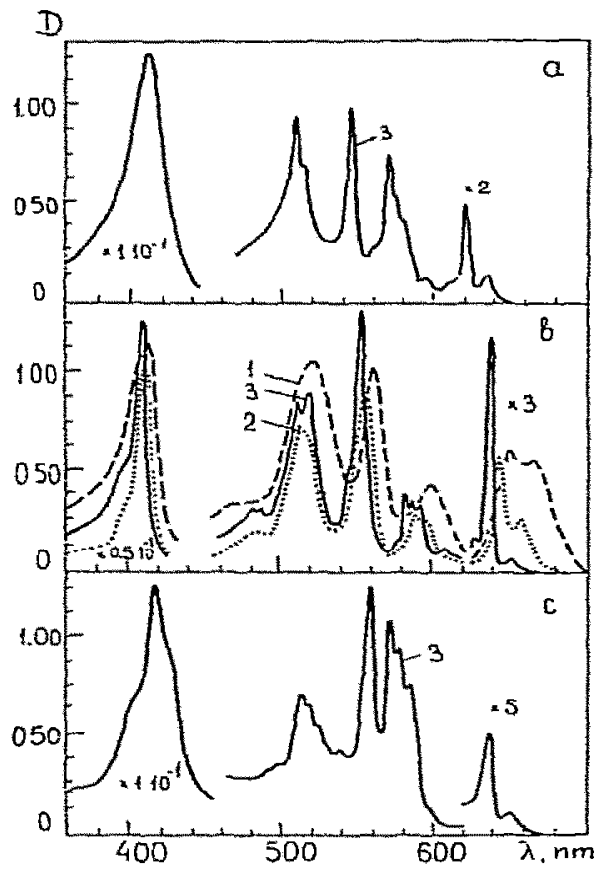

Fin. 1. Absorption spectrat of compounds 2 (a) and 9 (b) in EPIP and $5(\mathrm{c})$ in TH - DE. (1) $500 \mathrm{~K}$ (in methylnaphthalene). (2) $293 \mathrm{~K}$. (3) $77 \mathrm{~K}$.

is strongly dependent on the exciting light wavelength. It should be noted that the fluorescence lifetimes of the $0-0$ bands for the two luminescent centers, measured at $77 \mathrm{~K}$, are rather close (for example, in solution of compound $2 r_{1}=21.9 \mathrm{~ns}$ at $\lambda_{\text {reg }}=622 \mathrm{~nm}$ and $\tau_{2}=20.3 \mathrm{~ns}$ at $\lambda_{\text {reg }}=637 \mathrm{~nm}$ ). At room temper ature the spectral pattern is not so clear due to the temperature broadening and shift of the fluorescence bands. Nevertheless, in some cases additional bands can be observed even at $293 \mathrm{~K}$ (fig. 2b).

(c) Fucitation spectra of fluorescence (fig. 3). The analysis of Muorescence excitation spectra recorded at different emission wavelengths shows that the system of huorescence bands may be assigned only to two fluorescent centers. Comparison between different excitation spectra of fluorescence (fig. 3 ) and absorption spectra of the same compounds (fig. 1) permits us to conclude that in all the cases the two absorption centers are non-interacting. Clearly, at $77 \mathrm{~K}$ the existence of two centers which have their own fluoreseence and absorption spectra can be revealed for all

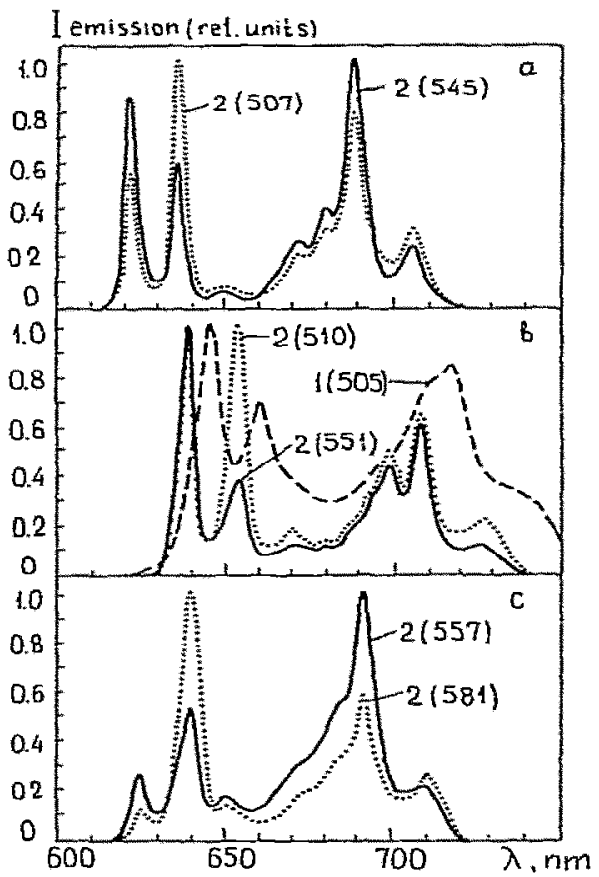

1"igy. 2. Fluorescence emission spectra of compounds $2(a)$ and 9 (b) in EPIP and 5 (c) in THIF-DE at $293 \mathrm{~K}(\mathrm{l})$ and $77 \mathrm{~K}$ (2). $\Delta \lambda_{\text {excit }}=4 \mathrm{~nm}, \Delta \lambda_{\text {monit }}=2 \mathrm{~nm}$. Excitation wavelengths are shown in parentheses.

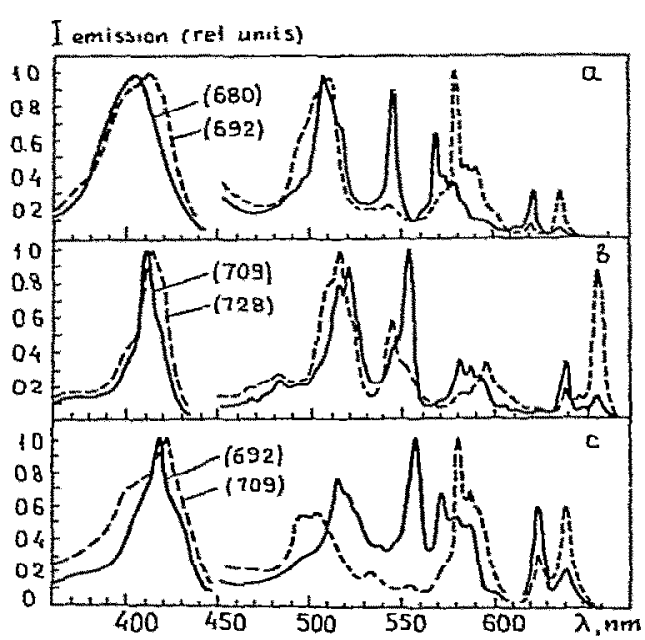

Fig. 3. Fluorescence excitation spectra of compounds 2 (a) and 9 (b) in EPIP and 5 (c) in THF-DE at $77 \mathrm{~K}$. The recording wavelengths are slown in parentheses. $\Delta \lambda_{\text {excit }}=2 \mathrm{~nm}$, $A \lambda_{\text {nonit }}=4 \mathrm{~nm}$. Correction of exciting light spectral distribution has been done up to $600 \mathrm{~nm}$. 
Table 1

Maxima of absorption and fluorescence spectra $(\lambda, \mathrm{nm})$, molar decimal extinction coefficients $\left(\epsilon \times 10^{-3}, \mathrm{~g} \mathrm{~mol}^{-1} \mathrm{~cm}^{-1}\right.$, in parentheses) and energy separation $\Delta E$ between $S_{0}-S_{1}$ transitions of tautomers in porphyrins with isocycle and their dimer

\begin{tabular}{|c|c|c|c|c|c|c|c|c|c|}
\hline \multirow[t]{2}{*}{ Compound } & \multirow{2}{*}{$\begin{array}{l}T \\
(K)\end{array}$} & \multicolumn{5}{|c|}{ Absorption } & \multicolumn{2}{|c|}{ Luminescence } & \multirow{2}{*}{$\begin{array}{l}\frac{a E}{\left(\mathrm{~cm}^{-1}\right)}\end{array}$} \\
\hline & & $B(0,0)$ & $Q_{1},(1,0)$ & $Q_{y},(0,0)$ & $Q_{x}(1,0)$ & $Q_{x}(0,0)$ & $\lambda^{0-0}$ & $\lambda^{\text {vib }}$ & \\
\hline 1 & 293 & $399(185)$ & $494(15.5)$ & $531(4.0)$ & $566(6.7)$ & $620(7.8)$ & 622 & 628 & 230 \\
\hline *a) & 77 & 399 & 499 & 532 & 560 & 612 & 614 & 679 & \multirow{2}{*}{260} \\
\hline$* *$ & 77 & 403 & 496 & 529 & 569 & 622 & 624 & 692 & \\
\hline 2 & 293 & $407(199)$ & $508(14.1)$ & $545(13.1)$ & $572(8.6)$ & $627(4.2)$ & 629 & 696 & 300 \\
\hline$\approx$ & 77 & 407 & 507 & 544 & 568 & $6 ? 1$ & 622 & 689 & \multirow[b]{2}{*}{380} \\
\hline$* *$ & 77 & 413 & 504 & 535 & 580 & 636 & 637 & 707 & \\
\hline 5 & 293 & $416(200)$ & $519(9.5)$ & $560(15.0)$ & $577(12.5)$ & $628(0.6)$ & 632 & 696 & 380 \\
\hline$*$ & 77 & 418 & 514 & 557 & 571 & 623 & 624 & 692 & \multirow{2}{*}{370} \\
\hline$* *$ & 77 & 420 & 507 & 533 & 581 & 638 & 639 & 709 & \\
\hline 7 & 293 & 419 & 524 & 566 & 586 & 639 & 641 & 710 & 320 \\
\hline$*$ & 77 & 423 & 523 & 568 & 590 & 637 & 638 & 707 & \multirow[b]{2}{*}{340} \\
\hline$* x$ & 77 & 426 & 513 & 546 & 592 & 651 & 652 & 726 & \\
\hline 8 & 293 & 425 & 526 & 568 & 590 & 644 & 649 & 716 & 260 \\
\hline$*$ & 77 & 429 & 530 & 570 & 588 & 643 & 644 & 714 & \multirow{2}{*}{240} \\
\hline$* *$ & 77 & 431 & 516 & 549 & 606 & 653 & 654 & 730 & \\
\hline 9 & 293 & $414(345)$ & $516(13.0)$ & $554(15.8)$ & $587(5.1)$ & $645(3.4)$ & 646 & 718 & 360 \\
\hline$*$ & 77 & 412 & 520 & 552 & 582 & 638 & 639 & 709 & \multirow{2}{*}{370} \\
\hline$* *$ & 77 & 413 & 513 & 543 & 594 & 653 & 654 & 728 & \\
\hline \multirow[t]{3}{*}{10} & 293 & $397(306)$ & $500(24.0)$ & $534(9.1)$ & $566(11.0)$ & $621(8.6)$ & 623 & 690 & 230 \\
\hline & 293 & $410(291)$ & $506(26.1)$ & $548(18.3)$ & $574(13.6)$ & $628(4.7)$ & 630 & 700 & 300 \\
\hline & 77 & 400 & 500 & 534 & 561 & 613 & - & - & 260 \\
\hline$*$ & 77 & 412 & 509 & 549 & 569 & 622 & 624 & 692 & \multirow{2}{*}{380} \\
\hline$* *$ & 77 & 423 & 501 & 534 & 580 & 637 & 638 & 709 & \\
\hline
\end{tabular}

a) * 1 tautomer: ** II tautomer.

isocycle-containing porphyrins (table 1). The spectral separation between the $S_{0}-S_{1}$ transitions of these centers is different as can be seen from table 1 . Therefore. it is difficult for some compounds to find the second center at $293 \mathrm{~K}$, but for compounds 2 and 9 , for example, this center can easily be detected even at higher temperatures ( 413 and $500 \mathrm{~K}$ ) (fig. Ib).

It should be noted that the existence of different centers is also found in the covalently linked diner 10. Moreover, the analysis of all data obtained for dimers points clearly towards the efficient transfer of the excited singlet state energy from two centers of compound 1 to two acceptor centers of compound 2 in dimers (these results will be published elsewhere). Increase in the porphyrin concentration by 300-700 times (say, for compounds 1 and 2) does not cause additional changes in electronic spectra as against diluted solutions. If the results obtained from temperature experiments (fig. $1 \mathrm{~b}$ ) and measurements of fluorescence lifetimes in different bands are taken into account, one may conclude that the additional centers observed in solutions of the investigated compounds are not due to porphyrin molecule aggregation. Below we present experimental results which clearly show that the two absorbing and fluorescing centers are due to $\mathrm{NH}$-tautomerism. 
(d) Photoinduced reversible conversion of the cen ters (fig. 4). Because of the intrinsic asymmetry caused by the isocyclic ring, the tautomers in the investigated compounds are chemically inequivalent and can absorb at rather different frequencies (see table 1). Therefore. it is possible to realize transformation between the two tautomers, which can be achieved by irradiating either of them in the region of the priority absorp$t$ ion. As can be seen fron fig. 4 , the fluorescence intensity of the first tautomer decreases in time upon excitation into its absorption band by constant (polarized or non-polarized) light. At the same time, the band of the first tautomer in the fluorescence excitation spectra decreases while that of the other increases. The reverse transformation can be realized by excit ing the solution into the absorption band of the second tautomer. It is essential that we could observe in such experiments not only a decrease in the fluorescence intensity of the first tautomer, but an increase in the fluorescence intensity of the other, too (fig. 4a. curve 3). Consequently, this photoprocess is cxactly phototransformation and not photodestruc-

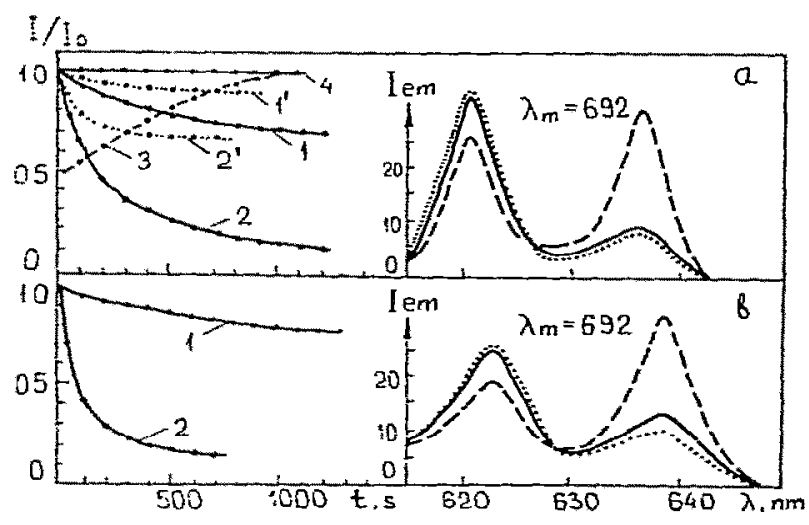

Fig. $\$$. Changes of fluorescence intensity and fluorescence excitation spectra of compounds 2 in EPIP (a) and 5 in TH1:-DE (b) with irradiation time at $77 \mathrm{~K}, \Delta \lambda_{\text {excit }}=4 \mathrm{~nm}$, $\Delta \lambda_{\text {monit }}=4 \mathrm{~nm}$. (a) (1), (1'): $\lambda_{\mathrm{ex}}=621 \mathrm{~nm}, \lambda_{\operatorname{mon}}=690$ nn: (2). (2'): $\lambda_{\mathrm{ex}}=636 \mathrm{~nm}, \lambda_{\operatorname{mon}}=690 \mathrm{~nm}\left(1^{\prime}\right.$ and $2^{\prime}-$ deuterded compound 2 in THF-DE); (3): $\lambda_{\mathrm{ex}}=622 \mathrm{~nm}$. $\lambda_{\text {mon }}=707 \mathrm{~nm} ;(4)$ : polyvinylbuthy ral film as a solvent, $T$ $=293 \mathrm{k}, \lambda_{\mathrm{ex}}=627 \mathrm{~nm}, \lambda_{\text {mon }}=697 \mathrm{~nm}$. (b) (1): $\lambda_{\mathrm{ex}}=623$ $\mathrm{nm}, \lambda_{\text {mon }}=692 \mathrm{~nm}:(2): \lambda_{\mathrm{cx}}=637 \mathrm{~nm}, \lambda_{\mathrm{mon}}=692 \mathrm{~nm}$. Excitation spectra:- initial: - - - after irradjatjon into the absorption band of the first tautomer; ... after irradiation into the absorption band of the second (lons-wavelength) tautomer. tion. The rate of transformation under the same excitation conditions is greater for long-wave tautomers than for short-wave ones, which is due to the existence of a potential barrier at photoinduced $\mathrm{NH}$-proton jumping at $77 \mathrm{~K}$. From the temperature dependence of the absorption spectra of compound 9 we found that the enthalpy of activation was $\Delta H_{\mathrm{N} 1 \mathrm{I}} \approx 530-570 \mathrm{~cm}^{-1}$ in the ground state.

We have also investigated the effect of deuterium substitution of the inner protons in the molecule center. For example the addition of deuterocthanol to THF-DE solution of compound 2 causes a significant difference between the kinetic curves and. consequently, the quantum efficiency of photoprocesses as compared with a similar case where normal ethanol is added (fig. 4a). This fact can readily be associated with the inhibition of ND-tautomerism as against NHtautomerism due to the growth of the mass of the jumping particles. Additional evidence of the $\mathrm{NH}$ tautomerism process is the observation of only one absorbing and luminescing form in solutions of the Zn-complex of compound 2 and its diprotonated de-. rivative and the absence of any phototransfornation processes under similar conditions. Finally, we have not observed any photoinduced transformations of the two tautomers of compound 2 in rigid films of polyvinylbuthiral at $293 \mathrm{~K}$. This lat ter result is due to the quick thermal migration of inner protons, which inhibits the photoselection of individual tautomers. So, directing our attention to the experimental part of the present work, it should be noted that for isocycle-containing porphyrins and their dimers, the spectral and energy character istics of individual NHtautomers can be detected with assurance when using normal electronic spectra. These objects are fairly convenient for the study of the detailed mechanism of tautomer photoinduced transformation. Such experiments are performed in our laboratory.

\section{References}

[1] J.J. Katz, J.R. Norris and L. L. Shipman, Brook haven Symposia in Biology No. 28 (1976) p. 16.

[2] V.A. Shuvalov and A.A. Krasnovsky, Biophysica 26 (1981) 544 .

[3] G.P. Gurinovich, A.N. Sevchenko and K.N. Solov'cv, Spektroskopiya khlorofilla i rodstvennykh soedinenii (Nauka i tekhnifia, Minsk, 1968). 
[4] K.N. Solov'ev. V.A. Mashenkov, A.T. Grady'ushko, A.E. Turkova and V.P. Lezina, Zh. Prikl. Spektroskopii 13 (1970) 339.

[5] E.I. Zalesski, V.N. Kotlo, A.N. Sevchenko, K.N. Solov'ev and S.F. Shkirman. Doklady Akad. Nauk SSSR 207 (1972) 1314

[6] O.N. Korotaev and R.l. P'ersonov. Opt. i Spektroskopiya 32 (1972) 400

[7] K.N. Solov'ev, 1.E. Zalesski. V.N. Kotlo and S.F. Shkirman. Pis'ma v ZhETl'h 17 (1973) 463.

[8] S.F. Shkirman, S.M. Arabey and G.D. Fgorova, Zh. Prikl. Spektroskopit 31 (1979) 817.

[9] S. Vôlker and R.M. Macfarlane, Mol. Cryst. Liquid Cryst. 50 (1979) 213.
[10] S.M. A rabey, G.D. Egorova, K.N. Solov'ex and S.I. Shkirman. Zh. Prik! Spektroskopii to (1984) 92.

1111 E.1. Zenkevich. A.M. Shulgu. A.V. Chernook and G.P. Gurinovich, Doklady Akad. Nauk BSSR (1984). to be published.

[12] G.V. Ponomarev. A.M. Shulga and V.P. Suboch. Dok lady Akad. Nauk SSSR 259 (1981) 1121.

[13] G.V. Ponomarev and A.IJ. Shulga. Doklady Akad. Nauk SSSR $271(1983) 365$.

14] G.U. Kenner, S.W. McCombie and K..M. Smith, J. Chem. Soc Peskin Trans. 1 (1973) 2517.

[15] G.W: Kenner, S.W. MeCombie and K.M. Smith, J. Chem. Soc. Perkin Trans. 1 (1974) 527.

(16) C. Housier and S. Sauer. Bipphys. Hiochim. setu 172 (1969) 49. 